\title{
Papel de la industria alimentaria y de la sociedad civil en los comedores comunitarios de SINHAMBRE. Casos de la Montaña y centro de Guerrero
}

\author{
Food industry and society on the SINHAMBRE \\ program soup kitchens. The Montaña and \\ Guerrero's center cases \\ doi: http://dx.doi.org/ \\ Fredyd Torres Oregón \\ Bruno Lutz*•
} 10.32870/espiral.v23i67.4484

\section{Resumen}

Este trabajo estudia cómo la implementación de los comedores comunitarios en la Cruzada Nacional contra el Hambre (SINHAMBRE) ha permitido que empresas de la industria alimentaria y de bebidas, así como organizaciones de la sociedad civil, difundan un modelo del buen comer que incorpora alimentos procesados en la dieta de los beneficiarios. La perspectiva histórica que guía la investigación encontró un punto de partida en la sugerencia de Bourdieu de investigar el interés del desinterés. Los resultados del estudio muestran que bajo el estandarte de la filantropía esas corporaciones transnacionales participan en SINHAMBRE para promover un mayor consumo de sus productos en comunidades rurales pobres. El examen de dos comedores comunitarios en Guerrero comprueba los efectos directos e inducidos de esta estrategia.

Palabras clave: comedores comunitarios, hábitos alimenticios, hambre, industria alimentaria, México.

\begin{abstract}
The main purpose of this research is to show that the implementation in Mexico of the soup kitchens of the Cruzada Nacional contra el Hambre (SINHAMBRE) has allowed food and beverage industries as well as civil society organizations to spread a model of a healthy diet which incorporates processed foods on the beneficiaries diet. The historical perspective that guide the research found a starting point in the suggestion of Bourdieu to investigate the interest of disinterestedness. The findings show that under the banner of philanthropy these transnational corporations participate in SINHAMBRE to promote a great consumption of their products in poor rural communities. The study of two soup kitchens in Guerrero provides information about the direct and induced effects of this strategy.
\end{abstract}

Keywords: soup kitchens, healthy eating habits, hunger, food industry, México.

\begin{abstract}
-Profesor-Investigador del Centro de Estudios e Investigación en Desarrollo Sustentable (CEDES) de la Universidad Autónoma del Estado de México.—zancamx@yahoo.com.mx - Profesor-Investigador de la Universidad Autónoma Metropolitana (UAM), campus Xochimilco.bbrunolutz0I@yahoo.com.mx
\end{abstract}

Fecha de recepción: 25 de noviembre de 2015. Fecha de aceptación: 26 de abril de 2016. 


\section{Introducción'}

Para atender a los más de siete millones de mexicanos que viven con hambre, el Gobierno de dicho país ha implementado la Cruzada Nacional contra el Hambre (SINHAMBRE) desde principios del 2013. Es el más reciente de los programas que se sucedieron en el transcurso del siglo XX y antes. SINHAMBRE reúne nueve programas, dentro de los cuales están los comedores comunitarios. Enfocándose en la alimentación de los más pobres, esta perspectiva asistencialista de nueva generación considera a los pobres como sujetos responsables de su situación, a quienes se tienen que inculcar buenos hábitos alimenticios.

La política de desarrollo social llevada a cabo desde hace tres décadas ha dejado a los campesinos pobres en la disyuntiva entre emigrar, dedicarse al cultivo de enervantes o sobrevivir en una pluriactividad precaria con algunos apoyos gubernamentales. La falta de compromiso gradual del Estado en el ámbito social ha permito a la sociedad civil y al sector empresarial ampliar su participación en programas de desarrollo, acorde a las sugerencias de las Naciones Unidas (ONU). Dentro de la región de América Latina y el Caribe, México es de las pocas naciones que cumplió la meta $1 \mathrm{C}$ de los Objetivos de desarrollo del milenio: reducir a la mitad, entre 1990 y 2015, la proporción de personas que padecen hambre (FAO, 2013, p. 3). ${ }^{2}$

I. El presente artículo se desprende de una estancia postdoctoral realizada en la UAM campus Xochimilco, como parte del proyecto de investigación núm. 334 I I448, "Inseguridad alimentaria en el medio rural. Caracterización, intervención institucional y respuestas", periodo enero-diciembre 2015, apoyado por el Consejo Nacional de Ciencia y Tecnología (CONACYT).

2. Los objetivos son: I) erradicar la pobreza extrema y el hambre; 2) lograr la enseñanza primaria universal; 3) promover la igualdad de género y el empoderamiento de la mujer; 4) reducir la mortalidad de los niños menores de cinco años; 5) mejorar la salud materna; 6) combatir el VIH-SIDA, el paludismo y otras enfermedades; 7) garantizar la sostenibilidad del medio ambiente; 8) fomentar 
Aun así, el problema del hambre sigue siendo grave, pues, derivados del entorno alimentario actual, se presentan fenómenos de subnutrición, malnutrición, obesidad y delgadez extrema, y sólo el 14\% de la población mexicana está bien nutrida (Del Castillo, 2013).

En el mismo periodo (1990-2015), México pasó a ser uno de los países con mayor número de personas con problemas de sobrepeso y obesidad. La Encuesta Nacional de Salud y Nutrición (ENSANUT) del 2012 reportó una prevalencia combinada de sobrepeso u obesidad de $34.4 \%$ en niños de cinco a once años de edad, 35\% en adolescentes de doce a diecinueve años, y 73.9\% en adultos mayores de veinte años (INSP, 2012, pp. 144, 162, 176). En su informe Panorama de salud Health at a Glance 2013, la Organización para la Cooperación y el Desarrollo presentó cifras similares (OCDE, 2013, p.1).

Esto significa que dos problemas se entrecruzan: la carencia de alimentos en el sector más vulnerable de la población, y una pandemia de obesidad que se extiende peligrosamente en todos los grupos etarios. Si bien el Gobierno afirma haber reducido a la mitad el número de pobladores con hambre, al mismo tiempo se encuentra frente a un grave problema de salud pública. ¿Por qué, entonces, haber implementado una "Cruzada" únicamente en contra del hambre y no en contra del exceso de peso? ¿Por qué los comedores comunitarios tienen una gran visibilidad en SINHAMBRE? ¿Qué motiva a los agentes empresariales y de la sociedad civil a participar -directa e indirectamente- en los comedores comunitarios? ¿Qué dicen los pobladores al respecto?

En el presente trabajo se responden estas preguntas analizando, desde una perspectiva macro-, el lanzamiento prematuro, pero mediático, de SINHAMBRE, y la búsqueda de recursos adicionales y la invitación a la sociedad civil

una alianza para el desarrollo. Información disponible en: http://www.un.org/es/ millenniumgoals/pdf/mdg-report-20I3-spanish.pdf 
y el sector empresarial a sumarse a esta iniciativa gubernamental. Dentro de esta biopolítica alimentaria, ${ }^{3}$ se pone atención más particularmente a los comedores comunitarios, su origen, gestión y alcances. Se examina el caso de comedores localizados en dos municipios de la Montaña, región de Guerrero. Sin pretender generalizar los resultados del trabajo de campo al conjunto de los comedores comunitarios que operan en todo el país, la información recabada sirve para ejemplificar el tratamiento institucional de los pobres y mostrar cómo SINHAMBRE busca "disciplinarlos" cambiando sus hábitos alimentarios.

De manera general, la estrategia metodológica fue la siguiente: se revisó la documentación oficial inherente a SINHAMBRE y la pobreza, y la información bibliohemerográfica y de medios de comunicación: prensa, audiovisuales e internet. Esto permitió retomar fragmentos del discurso de los agentes gubernamentales, económicos y sociales para ir integrando la comprobación de la hipótesis del trabajo. En seguida, se llevaron a cabo entrevistas a integrantes de organizaciones de la sociedad civil (OSC) y especialistas de SINHAMBRE en el Valle de Toluca y la Ciudad de México. Por último, se acudió a los municipios de Metlatónoc y Tixtla, en el estado de Guerrero, en los cuales se realizaron entrevistas directas con agentes locales e integrantes de los comedores comunitarios de las localidades de Metlatónoc y Atliaca, en el marco de un trabajo de campo.

La perspectiva teórica que guía a la presente investigación sobre el papel de la industria alimentaria, fundaciones y organizaciones dentro de SINHAMBRE encontró un punto de partida en la pertinente sugerencia de Bourdieu de investigar el interés del desinterés de los agentes. Pregun-

3. Se retoma el concepto de "biopolítica" desarrollado por Foucault (1975, p. 122) para designar al conjunto de juegos y mecanismos de poder destinados al control y regulación de la población, donde el saber-poder es el transformador de la vida humana.

\section{2}


tándose si un acto desinteresado es posible, el sociólogo francés contesta:

En la actuación de los agentes, hay una razón, que se trata de encontrar; y que permite dar razón, transformar una serie de comportamientos aparentemente incoherentes, arbitrarios, en serie coherente, en algo que quepa comprender a partir de un principio único o de un conjunto coherente de principios. La sociología postula que los agentes no llevan a cabo actos gratuitos (Bourdieu, 2007, p. 140).

La gratuidad, dice Bourdieu, puede aparecer como algo inmotivado, insensato, absurdo e insignificante. Sin embargo, este sentido de gratuidad suele significar también aquello que no vale nada, lo que no se paga, lo que no cuesta nada, lo que no es lucrativo. Por tanto, conviene examinar las estrategias de los agentes para aumentar su capital simbólico, entendido como el conjunto de representaciones, obligaciones, comportamientos, conductas que son propios a su clase de pertenencia.

Sobre esa base, Bourdieu (2007, p. 156) argumenta que pueden existir, de parte de los agentes, pretensiones universales que aparentemente carecen de un interés particular: la pobreza y el hambre, en el caso de este estudio. Asimismo, se acepta la idea de que en la mecánica pluri-institucional de los comedores comunitarios del programa SINHAMBRE se deben indagar las razones que motivan a los agentes de la sociedad civil y de la iniciativa privada para participar en este programa de alimentación de los pobres.

\section{Estado del arte}

Existe una vasta literatura acerca de la alimentación en México. Desde la perspectiva del poder de las transnacionales alimentarias y su influencia en las políticas alimentarias nacionales, destacan Bartra (2008), Cabada (2013), Ponce, 
et al. (2013), Rubio (2013, 2014), Torres Salcido (2010) y Veraza (2008).

Otros trabajos exploran la creciente dependencia alimentaria a partir de la apertura comercial (Rubio, 2013; Torres, 2014), mientras que en el campo de la antropología se han publicado estudios sobre los hábitos alimentarios de las poblaciones rurales (Gunder, 1982; Pilcher, 2001; Ortíz, et al., 2005; Bertram, 2006, 2007 y 2009; Good y Corona de la Peña, 2011; Juárez, 2013).

En cuanto al papel de las fundaciones caritativas y filantrópicas en la lucha contra la pobreza, destacan los escritos de Guadarrama (2001) y Lorenzo (2011). La lista es más extensa, pero por cuestión de espacio se citan sólo algunos de los trabajos relacionados con la alimentación en los estratos bajos de la población.

Por otro lado, pocas son las publicaciones académicas que evidencian cómo ciertos grupos económicos, políticos y organizaciones filantrópicas resultan beneficiados con la implementación de programas gubernamentales. No obstante, pueden enumerarse los trabajos de Montesinos y Martínez (2000), Delgado (2005), Arévalo (2012), González (2012), Camacho (2013), Rodríguez Castillo (2014), Rodríguez Wallenius (2014), Salas-Porras (2014) y Olmos (2015a). Estos estudios de caso respecto a la operación político-filantrópica de proyectos asistenciales ayudaron a comprender que la compleja lógica de intereses cruzados que están presentes en los comedores comunitarios no es exclusiva del programa SINHAMBRE.

3. Relación entre deterioro de la salud de los mexicanos y el crecimiento de las ganancias de las agroindustrias

Como se expuso en la parte introductoria de este trabajo, el número de mexicanos con exceso de peso se ha incrementado en los últimos quince años. La ENSANUT de 2006 reve- 
laba que el sobrepeso y la obesidad continuaban en aumento en todas las edades, regiones y grupos socioeconómicos. Las cifras más recientes indican que se tratan de los problemas de salud pública más importantes de ese año hasta la fecha (INSP, 2012, p. 124) (ver: Gráfica 1).

Gráfica 1. Prevalencia nacional combinada de sobrepeso y obesidad en México, 2006-2012, según rango de edad (millones de personas)

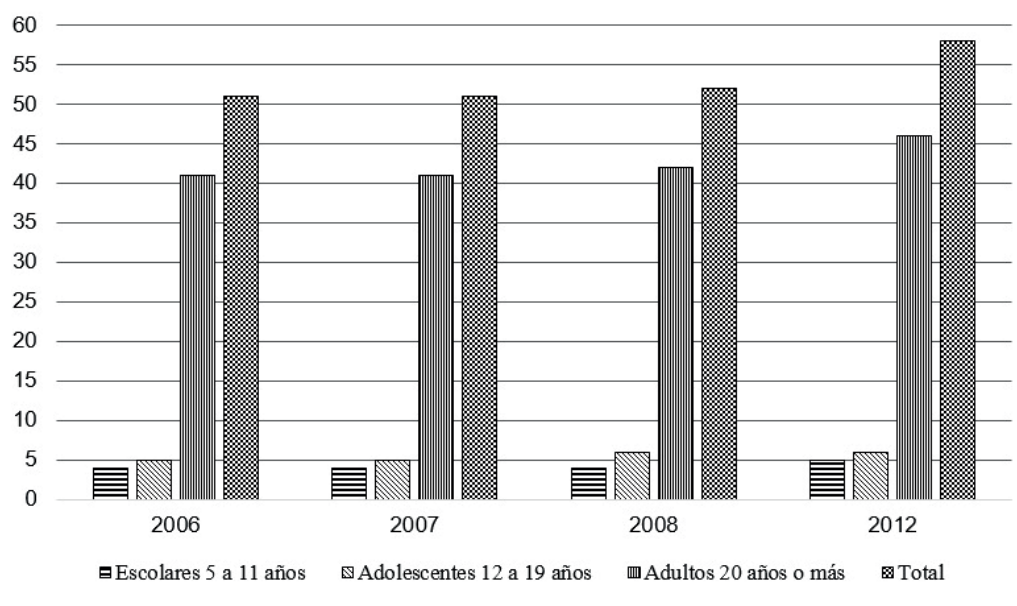

Fuente: elaboración propia con datos de INSP (2012) y CONAPO (2013).

González y Ángeles (2009) comentan que hasta los años ochenta predominaba en México una perspectiva epidemiológica que resaltaba la separación entre las enfermedades de la pobreza (infecciones, parasitosis), cuyo origen se reconoce en problemas alimentarios, y las enfermedades del desarrollo, que aluden a padecimientos de orden crónicodegenerativo. Es decir, se trata de un cambio del perfil de patologías asociadas a nuevos estilos de vida, por lo que se están dejando atrás patrones de enfermedades características de grados de desarrollo inferior (Arriaga, 1990; González y Ángeles, 2009, p. 153). 
El hecho de que más de la mitad de la población padezca sobrepeso u obesidad (con sus patologías conexas como la diabetes y las enfermedades cardiovasculares) tiene un impacto negativo sobre el presupuesto público destinado para la salud. De acuerdo a Beltrán y Beltrán (2011, p. 3), el gasto total anual en la atención médica de cuatro enfermedades atribuibles al exceso de peso en una proyección del 2008 al 2017 es de MXN 600000 millones aproximadamente (suma de gasto anual). Asimismo, los costos por enfermedades relacionadas con la obesidad alcanzan los USD 3500 millones al año, con USD 2000 millones al año asociados a los costos indirectos relacionados a los impactos en la productividad del país (Gómez Dantés, et al., 2011).

Por otra parte, sabemos que la pandemia de exceso de peso es consecuencia directa del consumo creciente de alimentos con altos contenidos de grasas saturadas, sales, azucares y harinas refinadas (Torres Salcido, 2011) y del consumo concomitante de grandes cantidades de bebidas saborizadas.

Esto último puede explicarse por el éxito de la publicidad de las agroindustrias, el precio económico y el fácil acceso de los refrescos, así como la idea que poseen los bajos estratos sociales de posicionarse en un nivel social más alto gracias a su consumo. Cabe señalar que el sobrepeso suele ser visto en las clases bajas como signo de salud y holgura económica (Ochoa Rivera, 2013). Asimismo, los problemas de sobrepeso y obesidad están asociados a factores de índole multifactorial: enfermedades, aspectos genéticos, culturales y el sedentarismo.

En ese sentido, existe una correlación entre la pandemia del exceso de peso y el consumo de productos de la industria alimentaria. De acuerdo con la Secretaria de Desarrollo Social (Sedesol), los grandes corporativos de la industria alimentaria son los mayores distribuidores de productos chatarra, por lo que contribuyen a incrementar los pro-

\section{6}


blemas de nutrición y enfermedades como hipertensión y diabetes, principales causas de muerte en el país (Dávila, 2013, p. 26).

Por su parte, Dariush Mozaffarian, rector de la Escuela Friedman de Políticas y Ciencias de la Nutrición de la Universidad de Tufts, en Estados Unidos, aseveró que en México el consumo de bebidas azucaradas es directamente responsable de la muerte de 24000 mexicanos cada año (Cruz, 2014, p. 45).

Ante la gravedad del problema, el Gobierno pretendió tomar medidas radicales mediante la aplicación de un impuesto al consumo de bebidas carbonatadas y azucaradas a través de la Ley del Impuesto Especial sobre Producción y Servicios, gravando un peso por cada litro de bebida vendida (Cámara de Diputados del H. Congreso de la Unión, 2015, p. 3).

No obstante la aplicación de esta medida hacendaria y la aprobación de un (laxo) reglamento para normar la venta de alimentos industriales en las escuelas, el estado de salud de la población se deteriora cada vez más, mientras incrementan las ganancias económicas de los principales grupos empresariales de la industria alimentaria y de bebidas. En la Gráfica 2 se enlistan algunas corporaciones de las llamadas "10 grandes", de acuerdo a Oxfam Intermón (2013). ${ }^{4}$

Las ventas de estas corporaciones agroalimentarias, de acuerdo con un reporte de la Secretaría de Economía (2013), alcanzó en 2012 un valor de USD 123954 millones, lo que representó un incremento del $2.3 \%$ con respecto a 2011. Así mismo, se estima que para el periodo 2012-2020 la producción de dicha industria tendrá una tasa media de crecimiento anual de 7.5\% (Secretaría de Economía, 2013, p. 13).

4. Se han enlistado sólo algunas empresas, pero la lista es mayor, con presencia en México y el mundo: Associated British Foods (ABF), Coca Cola, Danone, General Mills, Kellogg's, Mars, Mondelez International (antes Kraft Foods), Nestlé, Pepsico y Unilever. 
Gráfica 2. Ventas de la industria alimentaria y de bebidas en México y Latinoamérica 2007-2015 (miles de millones de pesos)

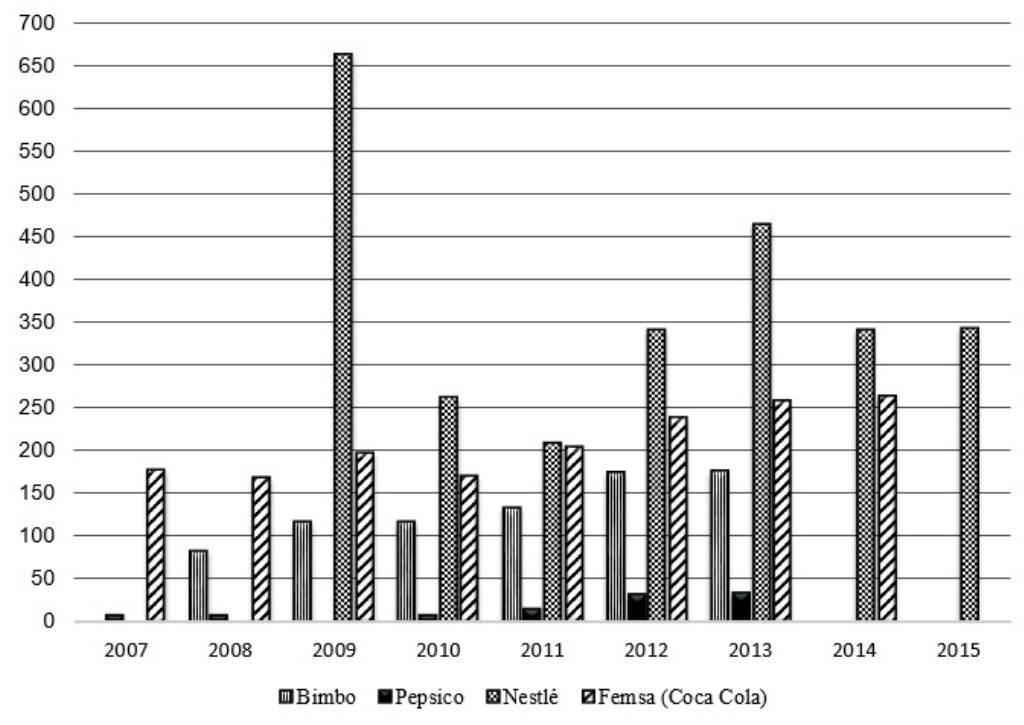

Fuente: elaboración propia con datos de informes financieros de las corporaciones (2007-2015) (ver: Anexo 1).

Sus productos se venden en todo el país: en tiendas de autoservicio, supermercados, tiendas de conveniencia, puestos de comida, tiendas de abarrotes, máquinas expendedoras, cines, restaurantes, estadios, entre otros. ${ }^{5}$ Por si esto fuera poco, algunas de estas corporaciones agroalimentarias en "los últimos diez años se han beneficiado con más de tres mil millones de dólares en aranceles no cobrados por conceptos de importación y beneficios de programas federales destinados originalmente al campo" (Dávila , 2013, p. 26). ${ }^{6}$

5. Un ejemplo: en el primer cuadro de la cabecera municipal de Metlatónoc, Guerrero, considerado uno de los municipios rurales más pobres del país y de América Latina, en cada calle céntrica hay más de cuatro establecimientos juntos que venden productos Coca Cola y de la empresa Bimbo (observación directa, 15 de mayo de 2014).

6. La autora detalla que emporios agroindustriales como Nestlé, Pepsico (Sabritas y Gamesa), Bimbo, Maseca, Minsa, ADN, Herdez, Jumex, Bachoco, Sukarne, Lala, 
Papel de la industria alimentaria y de la sociedad civil en los comedores comunitarios de SINHAMBRE. Casos de la Montaña y centro de Guerrero

\section{Empresas y fundaciones en la estrategia SINHAMBRE}

El programa SINHAMBRE nació con el decreto presidencial del 22 de enero de 2013. Sus objetivos son: 1) cero individuos con hambre a partir de una alimentación y nutrición adecuada de las personas en pobreza multidimensional extrema y carencia de acceso a la alimentación; 2) eliminación de la desnutrición infantil aguda y mejora de los indicadores de peso y talla de la niñez; 3) aumento en la producción de alimentos y el ingreso de los campesinos y pequeños productores agrícolas; 4) minimización de las pérdidas post-cosecha y de alimentos durante su almacenamiento, transporte, distribución y comercialización; y 5) promoción de la participación comunitaria para la erradicación del hambre. ${ }^{7}$

Son nueve los programas operados por la Sedesol que forman parte de la Cruzada (Sedesol, s/f), incluyendo a Prospera (antes "Oportunidades") y el Programa de Apoyo Alimentario (PAL SINHAMBRE), que ejecuta transferencias bancarias mensuales a través de la llamada "Tarjeta de Apoyo Alimentario" que permite adquirir un máximo de diecinueve productos ofertados por la paraestatal Diconsa: harina de trigo, leche en polvo, frijol, maíz, chocolate en polvo, avena, harina de maíz, café soluble, arroz, aceite de soya, atún, sardina, chiles enlatados, huevo fresco, lenteja, soya, amaranto, granola y pasta para sopa.

Cargill y Monsanto se han beneficiado de millones de pesos del presupuesto federal. Explica, por ejemplo, cómo las dos últimas han devastado la producción de maíz blanco mexicano y han manipulado los precios del maíz. Así mismo, documenta la política diferenciada para el campo: los mayores recursos son canalizados para la agroindustria del norte y el resto repartidos entre los pequeños productores. En suma, el crecimiento de la riqueza de los dueños de estas agroempresas alimentarias (algunos de ellos ya aparecen en la revista Forbes) se realiza mientras se deteriora la situación económica y el estado de salud de los trabajadores del campo y sus familias.

7. Información obtenida por vía del INAI, a través del número de solicitud 0002000159713 , en 2013. 
Sin duda, el programa que mejor caracteriza a SINHAMBRE es el de los comedores comunitarios, ${ }^{8}$ creados ex professo a partir de enero de 2013. Según datos oficiales, hay 3980 comedores comunitarios en todo el país, y más de la mitad de sus beneficiarios se encuentran en el Estado de México -entidad de origen del presidente de la república- y en Guerrero, siendo esta entidad federativa la que concentra el mayor porcentaje de población con carencia de acceso a la alimentación (SINHAMBRE, 2015).

Inicialmente, el Gobierno se propuso abarcar los cuatrocientos municipios del país con alta incidencia de pobreza extrema y atender a una población de 7.4 millones de personas (Coneval, 2013). Sin embargo, ante la "premura de ofrecer resultados de la Cruzada en el primer informe del presidente Peña Nieto, la meta inicial de abarcar cuatrocientos municipios de extrema pobreza se redujo a ochenta, la mayoría pequeños y rurales" (Turati, 2013, p. 6), mientras que "la población objetivo también disminuyó de 7.4 a 7 millones de mexicanos" (Gamboa, 2013, p. 125).

La Cruzada fue presentada ante la opinión pública mediante un gran despliegue mediático. El presidente de la república habló en esos términos:

Por eso fue que una de mis primeras decisiones presidenciales fue instruir la puesta en marcha de la Cruzada Nacional contra el Hambre, para sumar esfuerzos a favor de quienes viven en esta condición [...] esta es, sin duda, una de las iniciativas de mayor contenido social del Gobierno de la república. Es, también, la mayor obligación ética que

8. Debe mencionarse que la idea de crear comedores para alimentar a los pobres existe desde hace mucho tiempo. Ejemplos de ello son aquellos que fueron operados por las sociedades de beneficencia junto con el clero, los representados en el programa de desayunos escolares durante la Secretaría de Educación de José Vasconcelos (los cuales fueron integrados con comedores para alumnos de escuelas públicas en lugares apartados del medio rural), y finalmente los comedores escolares que en 2012 el Gobierno de la Ciudad de México implementó (Barquera, Rivera Dommarco y Gasca García, 200 I; Arrom, 2007). 
tenemos con toda la sociedad. Se trata de dirigir hacia un mismo objetivo los esfuerzos de los sectores público, privado y social, y [de que] haremos un frente común contra el hambre (Sagarpa, 2013).

Tres meses después de su inauguración, se instaló el "Consejo Nacional de la Cruzada contra el Hambre", en el cual la titular de Sedesol expresó su beneplácito por la incorporación de organizaciones civiles y filantrópicas que "han venido trabajando con los más pobres de este país" (Excélsior, 2013, s/p).

A esta convocatoria respondieron positivamente Cinépolis, Devlyn, la Central de Abastos, Wal-Mart, Nestlé y Pepsico. Mediante la firma de un convenio con el Gobierno, estas últimas dos empresas se comprometieron a mejorar la nutrición de los campesinos e indígenas pobres mediante la elaboración de galletas elaboradas a base de avena, en el caso de la segunda, y capacitar a las mujeres rurales en la elaboración de menús nutricionales, por parte de la primera. ${ }^{9}$ La titular de la Sedesol justificó la presencia de ambas empresas en SINHAMBRE:

La iniciativa privada es muy importante que participe en la Cruzada, y qué mejor que sea para los objetivos de la nutrición que están planteados en la Cruzada, es decir, que haya un realineamiento, una reorientación también de las estrategias de estos. Son empresas que son globales, que generan empleos en México y que tienen posibilidades de incidir. Por ejemplo, Pepsico, a través de su división de Quaker, que es [de productos de] avena, con el apoyo de investigación de la UNAM, con apoyo de otras instituciones [...] va a generar una galleta de bajo precio, que sea nutritiva y que nos permita llegar a estos municipios [...], y bueno,

9. Los productos Nestlé y las consecuencias de su consumo en las personas han sido asuntos cuestionados en todo el mundo. En Canadá, un estudio financiado por la compañía sobre una fórmula infantil llamada "Buen inicio", el cual demostraba que su consumo reducía las alergias de los niños recién nacidos, inclusive mejor que la leche materna, fue desmentido por la asistente del científico responsable, quien reveló que dicho estudio nunca fue realizado (INFACT Canadá, 2006). 
yo eso lo veo muy coherente, muy compatible con los objetivos de la Cruzada. En el caso de Nestlé, por ejemplo, nos va a aportar 200000 horas de capacitación en nutrición y nos va capacitar a 15000 mujeres para que tengan su propio negocio, su propia microempresa. Todo esto tiene que ver con los objetivos de la Cruzada, son totalmente coherentes, no podemos estigmatizar ni satanizar a nadie [...]. Todos podemos participar en esta causa, que nos atañe a todos, solidariamente tenemos que trabajar para que podamos superar esta condición en la que viven millones de mexicanos (CNN México, 2013a).

Una opinión diametralmente opuesta es la de Patti Rondall, integrante de una red internacional de grupos de la sociedad civil en pro de la alimentación infantil, ${ }^{10}$ quien señaló, en una entrevista con la periodista Carmen Aristegui, el peligro de incorporar a estos corporativos en políticas alimentarias:

Las veo como un cáliz envenenado [...] porque yo creo que las compañías fingen estar interesadas en el tema de hambre [...]. El tema de hambre es un buen encubierto para las compañías que venden alimentos porque todos tenemos hambre y necesitamos qué comer, pero ellas están utilizando esta palabra para fingir que están realmente interesadas en las personas más pobres [...]. Realmente están intentando penetrar el mercado mexicano y hacer que sus productos sean vistos como un esfuerzo filantrópico, quieren ser vistos como filantrópico[s] [...]. Estas compañías, Pepsico, Coca Cola, Nestlé, están confrontando críticas global[es] muy fuerte[s] [...]. Estas compañías venden productos muy peligrosos, son productos desnaturalizados, que no son frescos, y quieren que todos los países en vías de desarrollo consuman más de estos productos [...]. Esta es su manera de mejorar y de mostrarse, $y$ eso se convierte en su mayor prioridad de incrementar su margen

10. Incidencia es una fundación internacional con presencia en ciento setenta países del mundo e integrante también de una coalición contra conflictos de intereses que agrupa a ciento sesenta organizaciones y cuyo propósito es ayudar o salvaguardar las políticas públicas en materia de salud de los conflictos de interés comerciales a través de códigos de conducta ética en relación con los intereses privados. 
del mercado [...]. En México, que tiene una variedad de los mejores alimentos tradicionales, estas compañías quieren entrar a ese mercado [...], quieren entrar a cambiar los patrones de alimentación de la población y quieren introducir sus productos como algo mejor [...]. Es muy peligroso tener esas mismas compañías y participar como asociadas con el Gobierno en un proyecto muy importante (CNN México, 20I3b).

Ante la ola de críticas por la participación de Pepsico y Nestlé en SINHAMBRE, el Gobierno federal fue orillado a congelar los convenios suscritos con ambas corporaciones transnacionales. En la sesión de instalación del Consejo de Expertos, la titular de Sedesol confirmó que dichos convenios estaban detenidos (SINHAMBRE, 2013, p. 18), aunque en los lineamientos de este consejo Pepsico y la Fundación Wal-Mart siguen apareciendo como integrantes de las comisiones "Impulso de la producción agrícola del campo" y "Alimentación, nutrición, abasto y comercialización de alimentos eficientes y oportuna [sic] de las personas en situación de pobreza".

En todo caso, la Sedesol reorientó su estrategia hacia organizaciones de la sociedad civil no vinculadas a empresas transnacionales. ${ }^{11}$ En junio del 2014, firmó convenios con Un Kilo de Ayuda A. C., Oxfam, el Instituto de Nacional de Ciencias Médicas y Nutrición "Salvador Zubirán”, el Instituto Nacional de Salud Pública y el Banco de Alimentos de México (BAMX) (Sedesol, 2014). En entrevista personal para este estudio, un directivo de BAMX manifestó su convencimiento de la labor que hacen a favor de la alimentación de las familias de escasos recursos:

I I. El universo de las OSC es heterogéneo y muy diverso, pero, según los registros del Indesol, el $17.2 \%$ de estas apoya la alimentación popular, el $22.1 \%$ fomenta el desarrollo de los pueblos y comunidades indígenas, mientras que el $27.3 \%$ se dedica a la cooperación para el desarrollo comunitario. Esta información se obtuvo de una respuesta del Instituto Federal de Acceso a la Información (INAI) a solicitud personal de información, tarjeta número DRSAOSC/062/20I5. 
En el año 2014 repartimos 117000 toneladas de alimentos. El 65\% es fresco (frutas y verduras), y el resto alimentos industrializados. Los primeros los obtenemos de supermercados, comercios y centrales de abastos. Los segundos provienen de marcas como Nestlé, Kellogg's, Herdez, La Costeña, Gamesa, Kraft. Son productos que estas compañías donan porque [esto] les permite reducir sus inventarios, pero que aún están en buen estado, como son leche Nido, yogur, cereales, abarrotes, entre otros [...]. En México no hay dietas chatarras, pero sí hemos caído en una tendencia en consumir alimentos que no agregan valor nutricional, de allí que compañías como Coca Cola-Femsa, Nestlé y Kellogg's promuevan programas de educación y nutrición en la población (entrevista personal, 2015).

A pesar de la acción filantrópica de las fundaciones ligadas a la industria de alimentos y bebidas para mejorar el estado nutricional de un sector de la población, poco se ha logrado hasta el momento. Junto con el sector empresarial y la sociedad civil, el Estado se propone potencializar la capacidad de los pobres para que salgan de la pobreza (León, 2014). El combate a la pobreza alimentaria -verdadero leitmotiv bélico que guía el proceso contemporáneo de civilización de los que menos tienen- se enmarca dentro de la lógica capitalista del mercado.

La perspectiva que prevalece en la actualidad es considerar que los pobres alimentarios son responsables de sus carencias, y más especialmente las madres de familia, quienes tradicionalmente están a cargo de la preparación de la comida.

Suele estigmatizarse la producción de autoconsumo por los riesgos sanitarios que presenta el ingerir productos cuya inocuidad no ha sido previamente certificada, pero se denuncian también las conductas dietéticas de los pobres, quienes han convertido el consumo de sodas y golosinas en una competencia por capital simbólico, sin tomar en cuenta la legislación laxa al respecto ni las agresivas estrategias 
comerciales de la industria de alimentos y bebidas. De hecho, en el medio rural, los poblados más cercanos a las carreteras y las ciudades son los que concentran mayores problemas de salud relacionados con la mala alimentación.

Los nuevos hábitos alimentarios y estilos de vida conexos tienden a debilitar a los jóvenes haciéndoles más propensos a enfermarse. Para corregir esta situación, el combate de los "malos hábitos" privilegia la moralización de la alimentación de los beneficiarios de los programas de desarrollo social.

\section{Cambiar la dieta de los pobres en los comedores comunitarios de la Montaña de Guerrero}

La pobreza alimentaria en la región Centro y Montaña de Guerrero ha sido una de las más apremiantes de todo el país. Esta situación perdura a pesar de la multiplicación de los apoyos gubernamentales en las últimas décadas: el asistencialismo provoca efectos adversos. Por ejemplo, los recursos monetarios que reciben las beneficiarias del programa Prospera -programa que fue "recuperado" por SINHAMBRE- no siempre son utilizados para mejorar la dieta de sus familias. $\mathrm{Al}$ respecto, en las conclusiones de un estudio sobre los cambios alimenticios en la zona CentroMontaña, investigadores señalan:

El programa Oportunidades es un programa que se ha convertido [sic] en un ingreso importante para la gente, sin embargo, no fomenta la autosuficiencia y en los hechos, todo indica, ha favorecido el abandono del consumo de alimentos nutritivos y que formaban parte de la dieta tradicional para ser sustituidos por el consumo de alimentos procesados industrialmente con altos contenidos de azúcares, grasas y sal. A tal grado ha sido el impacto de Oportunidades en los cambios en la dieta, que existen evidencias que señalan que la población que recibe Oportunidades presenta niveles de desnutrición más altos que población del 
mismo nivel económico que no es beneficiaria del programa (El Poder del Consumidor, 2010, p. 38).

Se debe precisar que el programa Prospera (antes Oportunidades) no es enteramente responsable del sobreconsumo de refrescos y antojos: desde hace tiempo ya, poblados rurales como Metlatónoc y Atliaca están invadidos de productos de Coca Cola, Pepsico y Bimbo, marcas que poseen fundaciones y promueven programas de nutrición sana. ${ }^{12}$ En otras palabras, la intervención institucional en materia de alimentación reforzó la percepción positiva de los pobres en cuanto a las virtudes de los productos industriales y validó el prestigio simbólico otorgado a ciertas marcas.

Los cambios de patrones de consumo en las dos comunidades indígenas de estudio en el presente trabajo son evidentes, pues estas son parte de un mosaico territorial en el cual la presencia y demanda de productos de la industria agroalimentaria se han arraigado y hoy forman parte ya de sus hábitos alimentarios.

De acuerdo a un estudio realizado entre 2009 y 2010, en las zonas indígenas de las regiones Centro y Montaña de Guerrero el porcentaje de niños que toma bebidas gaseosas en el desayuno es de $70.3 \%$ en educación primaria, $60.0 \%$ en secundaria y $27.7 \%$ en media superior; en cuanto a la comida, los porcentajes de consumo son de $80 \%$ de niños en nivel secundaria, $73.4 \%$ de primaria, y $44.2 \%$ de preparatoria; entre comidas, los porcentajes son de $68.8 \%$ de los niños de primaria, $64 \%$ de los de secundaria, y el $21.5 \%$ de los preparatorianos. El porcentaje de niños de primaria que consume refrescos tres veces o más al día es de $59 \%$ (El Poder del Consumidor, 2010).

12. En el trabajo de campo realizado para esta investigación, tan sólo en el primer cuadro céntrico de la localidad de Atliaca se pudo constatar la presencia de sesenta y tres tienditas y expendios de Coca Cola y productos Bimbo (observación directa realizada en Atliaca el 2 de mayo de 2015).

\section{6}


En este sentido, el consumo de refresco en el desayuno ha sustituido al atole tradicional de maíz; según testimonio de un encuestado, este era "sagrado" y toda la familia lo tomaba. Ahora, sólo el 17.2\% de niños de primaria consume atole en el desayuno, contra el ya mencionado $70.3 \%$ que toma refresco. Incluso, el café soluble (no de grano) y los jugos de marca son de mayor agrado que el atole: en los niños de secundaria, el 52\% prefiere café y el $32 \%$ prefiere jugos de marca, contra $24 \%$ que prefiere consumo de atole (El Poder del Consumidor, 2010).

Finalmente, otra evidencia que muestra cómo se han modificado los patrones alimentarios en las comunidades rurales indígenas tiene que ver con lo que comen en sus escuelas. El estudio citado encontró que de los niños de primaria el 71.9\% consume frituras, el $68.8 \%$ dulces y el $45.3 \%$ pan dulce y galletas. Así mismo, los principales productos que se consumen entre comidas en niños de secundaria son frituras $(68 \%$ de los niños), refrescos (64\%) y refrescos y galletas (64\%).

Con los resultados expuestos, y extrapolando los mismos para los zonas rurales de Guerrero, es evidente que la población infantil y adulta está consumiendo grandes cantidades de carbohidratos, sodio, azúcares, sales y grasas refinadas que inciden en problemas de sobrepeso y obesidad, y por consecuencia en enfermedades asociadas: hipertensión, diabetes mellitus y enfermedades cardíacas. Las cifras más recientes de la Encuesta Nacional de Salud y Nutrición (INSP, 2012) muestran que en Guerrero, en niños de cinco a once años, el $27.2 \%$ padece sobrepeso y obesidad, cifra que en adolescentes de doce a diecinueve años es del 29.3\%. En el caso de adultos de veinte años o más (ambos sexos), el $38.4 \%$ padece sobrepeso y el $28.8 \%$ obesidad (INSP, 2012 ).

Entonces, el programa de comedores comunitarios de SINHAMBRE arrancó en un contexto de inseguridad alimentaria dominada por la generalización de hábitos alimentarios no saludables y problemas de salud relacionados. A raíz del 
paso del huracán Paulina y la tormenta tropical Ingrid, en septiembre de 2013, se conformaron comités de cocina en distintos poblados afectados en la región indígena de la Montaña de Guerrero, los cuales fueron asesorados por el Ejército en el marco del Plan DN III. ${ }^{13}$

Cuando los elementos de tropa concluyeron el curso, la supervisión de los trabajos del comité del comedor quedó a cargo de promotores civiles, en su mayoría jóvenes universitarios. No obstante, los soldados no han dejado de vigilar el funcionamiento de los comedores comunitarios. Al respecto, el comisario municipal de Atliaca expresó: "Nos vienen supervisando [los militares] una vez a la semana, dos veces, a veces hasta tres veces, y otras son supervisiones que llaman 'de sorpresa”' (entrevista personal, 2014a).

Tanto en los albergues como en los comités de cocina, los militares sirvieron muy a menudo alimentos procesados a la gente afectada por los desastres. La puesta en marcha del Plan DN III sirvió para que en el caso de los comedores comunitarios en la región, a más de dos años de su implementación, se siga un patrón alimentario compuesto en su mayoría de productos industriales. Esto pudo comprobarse en el poblado mixteco de Metlatónoc, de 3586 habitantes, así como en la comunidad nahua de Atliaca, que aglutina 5997 personas (Inegi, 2010). En Metlatónoc se instalaron tres comedores comunitarios: en la Escuela Secundaria Técnica 133, el Colegio de Bachilleres y la colonia Guadalupe. En Atliaca, el comedor comunitario se estableció en una casa particular prestada.

En el Cuadro 1, se describe parte del menú diario en dichos comedores. Cabe señalar que los alimentos propor-

13. La Secretaría de la Defensa Nacional estableció el Plan de Auxilio a la Población Civil en Casos de Desastre, denominado "Plan DN-III-E", un instrumento operativo militar que establece los lineamientos generales a los organismos del Ejército y Fuerza Aérea mexicanos para la realización de actividades de auxilio a la población civil afectada por cualquier tipo de desastre (Mendoza, 20I4).

\section{8}


cionados tanto en el almuerzo como en la comida deben supeditarse al menú previamente elaborado por los militares durante la fase de capacitación. Las cocineras pueden hacer combinaciones de platillos y variar el menú, siempre y cuando incorporen los alimentos listados por el Sistema de Distribuidoras Conasupo (Diconsa).

Cuadro 1. Características del funcionamiento de los comedores comunitarios en la cabecera municipal de Metlatónoc y Atliaca, Gro.

Menú semanal

Almuerzo (de lunes a viernes): atole de avena o leche y galletas.

Comida (de lunes a viernes):

Lunes: frijoles con sopa de arroz y atún y tortillas.

Martes: chilorio con huevo en polvo, espagueti y

tortillas.

Miércoles: machaca de res con huevo en polvo y tortillas.

Jueves: sardina, frijoles, espagueti y tortillas.

Viernes: carne de res deshebrada, frijoles y tortillas.

En ocasiones, se sirven duraznos en almíbar como postre.

\section{Población \\ atendida \\ diariamente \\ (promedio)* \\ Observaciones}

15-20 personas

La cuota de recuperación varía de MXN 3.00 a MXN 6.00 diarios. No hay consumo de frutas o verduras frescas; con el dinero de los cuotas de recuperación se compra chiles, cebolla, ajos, jitomate y leña (aproximadamente cincuenta leños al día con un valor de MXN 1.00 cada leño). En el comedor de la escuela secundaria se cuenta con dos cocineras a las que se les pagan a cada una MXN 100.00 diarios; en el resto se utiliza la participación voluntaria. En ningún comedor se cuenta con refrigerador. Las labores en los comedores son realizadas en su mayoría por mujeres, quienes inician sus labores a las 4:00 a. m. y terminan a las 5:00 o 6:00 p. m.

* Si bien al principio de la puesta en marcha del programa, de acuerdo a integrantes del comité entrevistadas, el número de personas asistentes al comedor oscilaba en alrededor de treinta personas (entre mujeres, niños y de la gente de la tercera edad), a medida que ha pasado el tiempo la afluencia se ha visto muy disminuida. Incluso se ha permitido que algunos beneficiarios lleven la comida del comedor a su casa.

Fuente: elaboración propia con base en observación directa en estudio de sitio realizado los días 13 de mayo de 2014 y 2 de mayo del 2015. 
Cuadro 2. Tipo de alimentos surtidos por Diconsa en los comedores comunitarios del estado de Guerrero (2014)

Aceite vegetal

Agua potable

Arroz

Atole para bebida

Atún en aceite o agua

Avena en hojuelas

Azúcar

Frijol

Galletas marías

Galletas saladas

Harina de maíz

Leche en polvo

Leche líquida ultrapasteurizada

Lentejas

Mayonesa

Pasta para sopa

Pasta tipo espagueti

Soya texturizada natural

Chicharos en lata

Elote
Jugo de fruta

Coctel de frutas en almíbar

Puré de tomate

Chile chipotle

Chile jalapeño

Huevo en polvo

Sal

Café molido

Canela

Chile guajillo

Concentrado para agua

Consomé de pollo

Salsas

Verduras (surtido de verduras)

Barbacoa de res

Carne deshebrada

Chilorio de cerdo

Machaca de res

Sardina

Fuente: respuesta del Instituto Federal de Acceso a la Información (INAI) a solicitud de información número 0002000005614, realizada en 2014.

Los alimentos enlistados en el Cuadro 2 corresponden a los "Lineamientos específicos del Programa Comedores Comunitarios en el marco de la Cruzada contra el Hambre para el ejercicio fiscal 2013", que a la letra dicen:

Los alimentos diarios que se preparen en los comedores comunitarios deberán aportar las necesidades nutricionales básicas a la población atendida, de tal manera que las raciones diarias referenciales por individuo contemplarán la presencia de cereales, proteínas y vegetales, adecuado a lo establecido en la Norma Oficial Mexicana NOM-0I4-SSA3-20I2. Asimismo, la preparación de los alimentos debe contemplar los factores culturales de tipo culinario de la zona, la utilización de insumos de la región y la incorporación de alimentos externos sanos de alto contenido nutrimental de aceptación comunitaria, para los diferentes grupos etarios (Sedesol, 2013, p. 18). 
A pesar de estas loables recomendaciones, en los comedores comunitarios visitados se comprobó que se sirven en su gran mayoría alimentos ajenos a los hábitos de los pobladores: huevos en polvo, granos de elote en lata, carne seca deshebrada, soya, verduras enlatadas, chilorio, machaca de res en bolsa, sardina enlatada, atún enlatado, barbacoa de res enlatada y coctel de frutas en almíbar enlatado. Los pocos alimentos frescos (chiles, cebollas y ajos) son comprados gracias a la cooperación de los comensales.

En el mismo sentido, el director de la Secundaria Técnica 133 señaló: "No hay variedad en el menú [...] o son frijoles o sopa, a veces atún, soya [...], pero estos últimos no les gusta a los muchachos [...], bueno, se da el caso de que los del comité les dan a los muchachos huevo en polvo para que se lo lleven a sus casas, pero lo tiran, yo me he encontrado bolsas tiradas en el camino" (entrevista personal, 2014b).

A pesar del consumo generalizado de refrescos y antojos, los pobladores de la región Montaña-Centro de Guerrero rehúsan comer huevos deshidratados, leche en polvo, soya, atún y sardinas enlatadas. De hecho, suelen enfermarse al ingerir esos alimentos, por lo que, en su gran mayoría, prefieren abstenerse de consumirlos, o bien los dan a sus animales. Los consideran como alimentos de pobres. Tienen la idea, no del todo equivocada, de que les regalan alimentos que la gente de la ciudad no come. Asimismo, ingerir esos alimentos los desvaloriza simbólicamente a los ojos de sus familiares, vecinos y de la comunidad en general.

Si bien las precarias condiciones de almacenamiento dificultan la buena conservación de alimentos frescos en los comedores comunitarios, cabe señalar que los productos enlatados de larga conservación no ofrecen las mismas propiedades bromatológicas que las verduras, frutas y carnes frescas, además de que sus presentaciones y sabores no siempre agradan a los consumidores del medio rural. 
Además, cabe agregar que el asistir a los comedores comunitarios se ha vuelto un estigma entre los mismos pobladores: son vistos dentro de la comunidad como "pobres", y el ama de casa de estas familias es criticada, por lo que una parte de los beneficiarios opta por llevar sus alimentos a sus hogares y comerlos allí. Están acostumbrados a reunirse en la cocina de su casa y compartir los alimentos que la esposa-madre de familia ha preparado.

En esas comunidades rurales, los alimentos se preparan generalmente con productos frescos y se guisan el mismo día. La frescura de los ingredientes y el comerlos calientes son elementos que valoran los pobladores, además de acompañar la comida con gran cantidad de sodas. El romper esta costumbre representa un riesgo para la armonía familiar y trastorna la vida doméstica de los pobladores rurales.

Esta es una de las razones -junto con la oferta de guisados preparados con alimentos procesados-por las cuales el número de consumidores en los comedores comunitarios es relativamente bajo (a pesar de las elevadas cifras presentadas por los responsables ante la Sedesol). Los pobladores deben de estar en una situación de absoluta penuria y no tener nada que comer en su casa para enfrentar el estigma social de acudir al comedor comunitario.

En otras palabras, los comedores se han convertido en un espacio de "descalificación" (déclassement) que estigmatiza, a los ojos de la comunidad, a los más pobres entre ellos. A una lógica comunitaria que tiene sus reglas no dichas y sus códigos culturales, se opone con frecuencia una lógica asistencialista de corte occidental basada en el minucioso registro de cada una de las intervenciones que realiza.

Precisamente, conviene ahora examinar la monetarización de la acción filantrópica de las principales organizaciones de la sociedad civil que participan en el programa de comedores comunitarios. Las Gráficas 3 y 4 muestran el papel preponderante de la organización Un Kilo de Ayuda

\section{2}


Papel de la industria alimentaria y de la sociedad civil en los comedores comunitarios de SINHAMBRE. Casos de la Montaña y centro de Guerrero

A. C. en cuanto a la captación de recursos públicos en el marco del programa SINHAMBRE.

Cabe recordar que el origen de esta organización remonta a 1984, cuando fue fundada "Gente Nueva" respaldada por los Legionarios de Cristo. A partir de esa fecha, el influyente grupo de católicos seguidores del padre Marcial Maciel creó tres proyectos emblema de la Legión: Un Kilo de Ayuda, en 1987, Compartamos, en 1991, y Fundación México Unido, en 1994 (Olmos, 2015). Con sus oficinas ubicadas en una exclusiva colonia de la Ciudad de México, y siendo dueña de una muy extensa red de contactos entre políticos y empresarios, Un Kilo de Ayuda A. C. afirma en su página internet trabajar en el estado de Guerrero, sin dar mayores precisiones al respecto.

Gráfica 3. Recursos públicos recibidos por un Kilo de Ayuda A. C. y equipamiento de comedores rústicos comunitarios en dos municipios de Guerrero (datos en MXN). Periodo 2014-2018

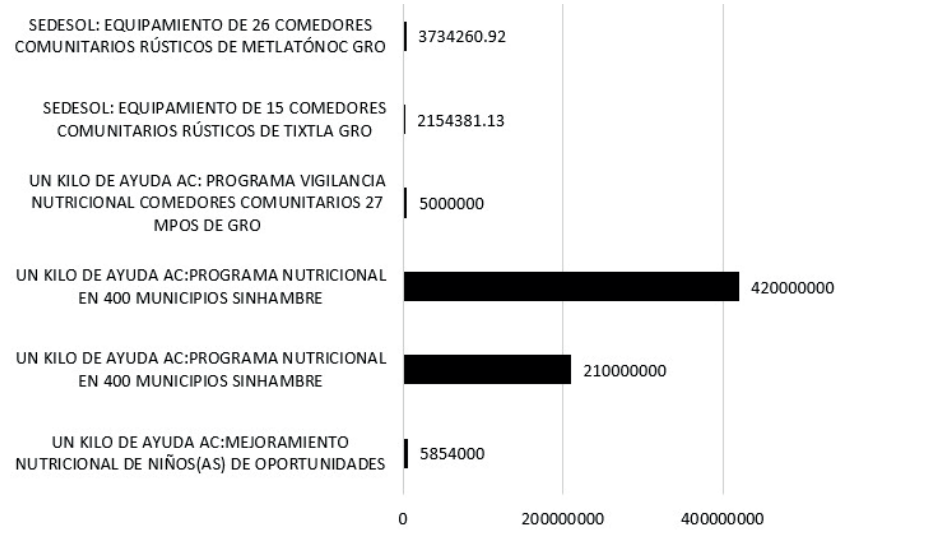

Fuente: elaboración propia con datos de solicitudes de información realizadas al INAI, con número de folio 0002000021515, el 22 de mayo 2015, y 0002000081615 , el 16 de julio de 2015.

14. Los montos de recursos para los años 2016, 2017 y 2018 destinados para un Kilo de Ayuda A. C. son proyectados con información de la solicitud de información realizada al INAI con número de folio 000200002 I5I5, del 22 de mayo 2015. 
Gráfica 4. Recursos públicos recibidos por OSC para capacitación nutricional y buenos hábitos alimentarios (datos en MXN)

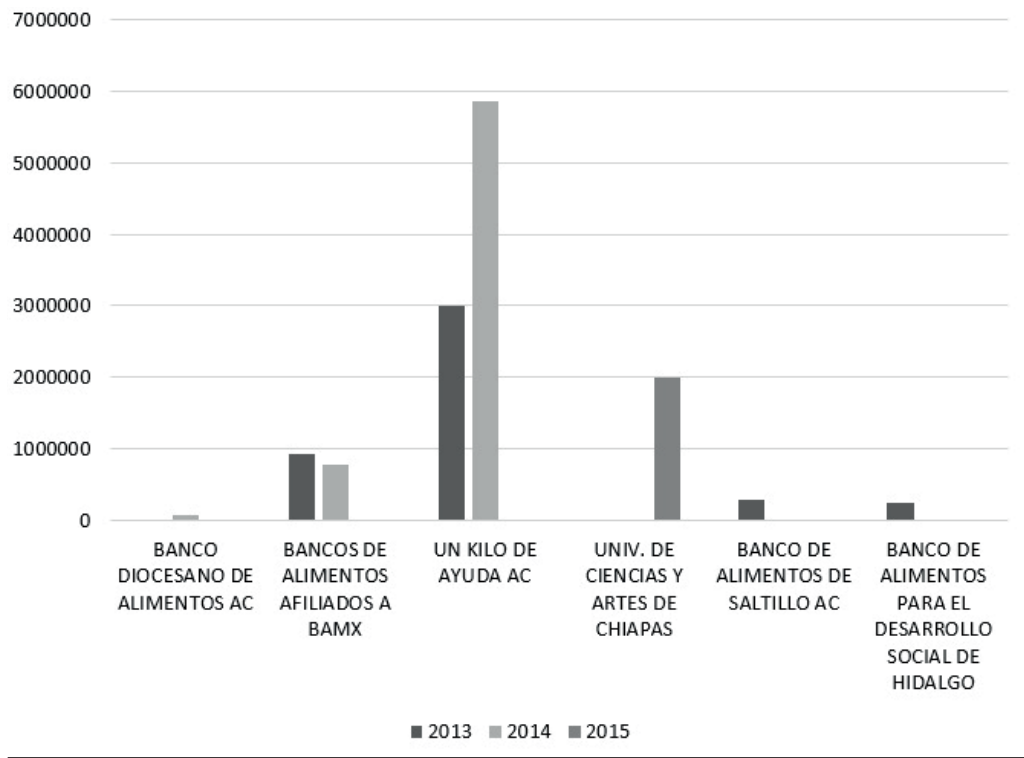

Fuente: elaboración propia con información de respuesta a solicitud de información al INAI, número de folio 0002000021515 , realizada el 22 de mayo 2015, así como de sitios electrónicos de OSC.

La desproporción a favor de Un Kilo de Ayuda -cuyos dirigentes reconocen no invertir todo en la alimentación de los pobres (Proceso, 2003) - en cuanto a la captación de recursos muestra que la acción filantrópica, en este caso guiada por motivos religiosos, no garantiza por sí misma ni su efectividad ni su transparencia.

Las fundaciones bien posicionadas en el escenario nacional, como Un Kilo de Ayuda, y la red de Banco de Alimentos son favorecidas, a diferencia de organizaciones filantrópicas de menor peso económico, mediante cuantiosos recursos públicos para implementar programas de vigilancia nutricional y rehabilitar o construir inmuebles para bancos de alimentos, como son las casos de Banco de Alimentos de 
Guanajuato, A. C., Banco Diocesano de Alimentos de los Altos, A. C., Cáritas Diocesanas de Torreón, A. C., y Banco de Alimentos de Zapotlanejo, A. C. (por citar algunas), que en conjunto recibieron MXN 24462367 por dichos conceptos en el año $2014 .^{15}$

Los mecanismos sobre cómo estas fundaciones reciben recursos públicos están asociados en primera instancia a las estrechas relaciones que mantienen con la clase gobernante $y$, en segunda, a su participación en licitaciones abiertas o cerradas llevadas a cabo por las diferentes dependencias gubernamentales. Según su perfil e historial, las OSC pueden también solicitar donativos privados a determinadas empresas.

En todo caso, las donaciones de las empresas a OSC están reguladas por la Ley Federal de Fomento a las Actividades de Desarrollo Social de las Organizaciones Civiles, que precisa las actividades que pueden recibir apoyos económicos. En cuanto al Código Financiero del Distrito Federal (Gaceta Oficial del Distrito Federal, 2008, pp. 38-301), este autoriza una reducción de $100 \%$ al impuesto predial y el impuesto sobre la nómina de dichas organizaciones, y el artículo 31 de la Ley del Impuesto Sobre la Renta (ISR) acota a 7\% de la utilidad fiscal lo que las empresas pueden deducir de impuestos.

Más allá de la filosofía de "empresa socialmente responsable”, que puede llegar hasta la creación de sus propias fundaciones, el sector empresarial tiene la posibilidad de recurrir a las medidas fiscales antes señaladas para posicionarse ventajosamente en el ámbito filantrópico, promoviendo al mismo tiempo una imagen positiva de la marca ante la opinión pública y los consumidores.

I5. Según información obtenida en respuesta a solicitud hecha al INAI, con folio 000200002 I5I5, en 2015. 


\section{Conclusiones}

SINHAMBRE se ha erigido mediáticamente en una política ejemplar para combatir la carencia de alimentos en las zonas marginadas. Aplaudido en la escena internacional y fuertemente criticado en el país, este meta-programa coordina muchos otros programas operados por diferentes secretarías, uno de los cuales es el de los comedores comunitarios.

El lanzamiento precipitado de la Cruzada contra el Hambre, con recursos limitados y estrategia no precisa, redujo las expectativas del Ejecutivo federal en cuanto a su capacidad de terminar con el hambre, tal como se comprometió el Gobierno mexicano al suscribir los Objetivos del milenio de la ONU.

La polémica inicial en torno a los municipios en los cuales iba a operar mostró los intereses partidistas que estaban detrás de este listado y la capacidad de SINHAMBRE para convertirse en un instrumento de lucha contra insurrecciones en los municipios donde existe pobreza y movimientos de protesta. Los comedores comunitarios de la Cruzada Nacional contra el Hambre se han constituido como un dispositivo institucional (en el sentido de Foucault -1994, p. 299-) sobre la base de múltiples tácticas de control y manipulación de la pobreza en el medio rural.

Por otro lado, se ha mostrado que más allá de buscar soluciones al problema alimentario con los propios pobladores rurales, SINHAMBRE ha servido como plataforma para la participación "desinteresada" de empresas de la industria alimentaria y fundaciones en el manejo de proyectos específicos de dicho programa. Aunque ante la opinión pública la industria alimentaria expresa su interés para mejorar la nutrición de los pobres, no dejó de cabildear por una legislación más laxa y promover nuevas estrategias comerciales

\section{6}


que dieron como resultado, por ejemplo, el aumento constante del consumo de bebidas endulzantes y carbonatadas.

En los hechos, la comida local está desvalorizada en los comedores comunitarios, ya que se siguen consumiendo productos mayoritariamente enlatados y procesados, en detrimento de alimentos frescos. Se infiere que el alcance de los convenios firmados entre la Sedesol y las empresas y OSC es mayor a lo que plasma su contenido: en efecto, se busca sigilosamente modificar la dieta cotidiana de los pobres para integrar aún más alimentos procesados.

Generalmente, las fundaciones se acoplan a las exigencias institucionales, siguen las recomendaciones de sus donadores y promueven los modelos dietéticos hegemónicos. Se puede aseverar que existe una convergencia de intereses para seguir llevando a cabo el proceso de civilización alimentaria de los pobres.

Más allá de la difusión mediática de los logros cuantitativos de SINHAMBRE en medio de una estrategia discursiva autocomplaciente, el trabajo de campo en dos poblados del estado de Guerrero no permitió encontrar evidencias contundentes en cuanto a una disminución de las carencias alimentarias de la población. La incorporación mayoritaria de alimentos enlatados, la supervisión de los comedores comunitarios por el Ejército, la burocratización del abasto y operación de los mismos, así como la gestión discrecional del almacén por las voluntarias son factores que tienden a nulificar los efectos positivos que podría tener dicho programa.

Este asistencialismo alimentario de "nueva generación", o neoinstitucional, recurre al voluntariado de los mismos beneficiarios para responsabilizarles de sus carencias. Los comedores comunitarios conllevan una indiscutible carga moral. Estos programas alimentarios contribuyen a reforzar el proceso de cambio de hábitos alimentarios de los autóctonos cuando estos sustituyen, libre y gradualmente, su dieta tradicional por el consumo inmoderado de productos 
saturados en azúcar, grasa y sal. Asimismo, SINHAMBRE mediante sus diferentes vertientes- valida indirectamente la ingestión de alimentos procesados y, por ende, promueve el modelo occidental del buen comer.

Bibliografía

Arévalo, P. M. L. (2012). Prácticas espaciales y socioeconómicas en la ciudad rural sustentable "Nuevo Juan del Grijalva” (tesis de maestría inédita). CIESAS: San Cristóbal de las Casas. Recuperada de: http://repositorio. ciesas.edu.mx/bitstream/handle//23456789/I58/M54I. pdf? sequence $=\mid$ \&isAllowed $=y$

Arriaga, E. (1990). Causas de muerte en la mortalidad general y adulta de México 1980-1985. México: U. S. Bureau of the Census.

Arrom, S. M. (2007). "Las Señoras de la Caridad: pioneras olvidadas de la asistencia social en México I863-1910". Historia Mexicana, 57(2), 445-490.

Barquera, S., Rivera Dommarco, J., y Gasca García, A. (200I). "Políticas y programas de alimentación y nutrición en México”. Salud pública de México, 43(5), 464-477.

Bartra, A. (2008). "Fin de la fiesta. El fantasma del hambre recorre el mundo". Argumentos, (57), 5-3I.

Beltrán, L. F., y Beltrán, F. J. (20II). "Obesidad infantil un problema de salud pública”. Revista Electrónica Medicina, Sociedad y Salud, 2(I), I-9. Recuperado de: http:// cienciasdelasaluduv.com/revistas/index.php/mss/article/ view/48/pdf_I8

Bertram, M. (2006). "La alimentación indígena de México como rasgo de identidad”, en A. L. Alonzo Padilla, y F. Peña Saint Martin (coords.), Cambio social, antropología y salud (Pp. 167-175). México: Conaculta-INAH.

- (2007). "¿Orientación alimentaria o los diez mandamientos? La moral en los discursos de la nutrición 
y la salud", en B. León Parra, y F. Peña Saint Martin Bibliografía (coords.), Antropología fisica, salud y sociedad. Viejas tradiciones y nuevos retos (pp. 147-I53). México: ENAHINAH-Conaculta.

(2009) "Reflexiones sobre al análisis antropológico de la alimentación”, en A. E. Castro Sánchez (coord.), Salud, nutrición y alimentación: investigación cualitativa (pp. 4 I-64). México: Universidad Autónoma de Nuevo León. Bourdieu, P. (2007). Razones prácticas sobre la teoría de la acción. Barcelona: Anagrama.

Cabada, X. (I 6 de febrero de 20I3). "La industria alimentaria impone criterios de nutrición”. La Jornada del Campo, p. 12.

Camacho, V. D. (20I3). "Las ciudades rurales chiapanecas: ¿el fin de la dispersión y la pobreza o formas novedosas de control social?"en M. Aguilar Rivero, O. V. Avilés Hernández, y C. A. Aguirre Álvarez (eds.), Depredación: ciudades rurales, comunidades intervenidas y espacios en conflicto (PP. 185-204). México: UNAM-Juan Pablos Editor.

Cámara de Diputados del H. Congreso de la Unión (20I5). Ley del Impuesto Especial sobre Producción y Servicios. México: H. Congreso de la Unión. Recuperado de: http://www.diputados.gob.mx/LeyesBiblio/ pdf/78_24I2I5.pdf

Coneval (20l3). Diagnóstico del Diseño de la Cruzada Nacional contra el Hambre. Recuperado de: http://web. coneval.gob.mx/Informes/Evaluacion/Cruzada\%20 contra\%20el\%20Hambre/RESUMEN_DIAGNOSTICO_ DISE\%C3\%9IO_CNCH_OCTUBRE.pdf

CNN México (II de abril de 20I3a). "El apoyo de empresas para combatir el hambre es 'coherente': Rosario Robles". Recuperado de: http://mexico.cnn.com/nacional/20 I 3/04/ I I/el-apoyo-de-empresas-para-combatirel-hambre-es-coherente-dice-robles 
(19 de marzo de 2013b). "“Cruzada contra el Hambre en México': entrevista de Carmen Aristegui a Patti Rondall" (material audiovisual en línea). Recuperado de: https://www.youtube.com/watch?v=HJs8inSG0rQ CONAPO (20I3). Indicadores demográficos básicos 19902010. Recuperado de: http://www.conapo.gob.mx/ es/CONAPO/Indicadores_Demograficos_Basicos_1990-2010

Cruz, M. A. (12 de noviembre de 20I4). "Mueren 24 mil mexicanos cada año por consumo de bebidas azucaradas: experto". La Jornada. Recuperado de: http://www. jornada.unam.mx/20 I 4/ I I/ / /sociedad/045n I soc

Dávila, P. (20I3). "Combate al hambre, para beneficio de las trasnacionales". Proceso, (1902), 26-29.

Del Castillo, M. (20I3). "El hambre en México". Estudios, XI( I07), 7 I-I I I. Recuperado de: http://www.exalumnos. itam.mx/Estudios_dic /3/El-hambre-en-mexico-paraCONEXION.pdf

Delgado, A. (2005). "Filantropía con interés". Proceso, (1475), 6-10.

El Poder del Consumidor (2010). Impacto de la presencia de comida chatarra en los hábitos alimenticios de niños y adolescentes en comunidades indígenas-campesinas de la región Centro-Montaña de Guerrero. México: El Poder del Consumidor-Oxfam-GEA.

Excélsior (20I3). "Instalan Consejo Nacional de la Cruzada Nacional contra el Hambre”. Recuperado de: http:// www.excelsior.com.mx/nacional/20 I 3/04/ I 0/893268

FAO (20I3). Panorama de la seguridad alimentaria y nutricional en América Latina y el Caribe 2013. Hambre en América Latina y el Caribe: acercándose a los Objetivos del Milenio. Recuperado de: http://www.fao.org/docrep/019/i3520s/ i3520s.pdf

Foucault, M. (1975). Vigilar y castigar. México: Siglo XXI. (1994). Dits et écrits. Vol. III. París: Gallimard. 
Gaceta Oficial del Distrito Federal (27 de diciembre del 2008). Bibliografía Código Financiero del Distrito Federal. México: Gobierno del Distrito Federal.

Gamboa, C. (20I3). "Cruzada contra el hambre". Dirección de Servicios de Investigación y Análisis. Recuperado de: http://www.diputados.gob.mx/sedia/sia/spi/SAPIISS-84-I3.pdf

Gómez Dantés, H., Castro, M. V., Franco Marina, F., Bedregal, P., et al. (20II). "La carga de la enfermedad en países de América Latina”. Salud Pública en México, 53(2), 572-577. Recuperado de: http://www.scielo.org. $\mathrm{mx} / \mathrm{pdf} / \mathrm{spm} / \mathrm{v} 53 \mathrm{~s} 2 / 03 . \mathrm{pdf}$

González, A. (20I2). "Desigualdad y políticas públicas en situación de conflicto" (ponencia en el marco del Foro Exclusión... inclusión neoliberal. Miradas sobre las Ciudades Rurales Sustentables: la vida en la Ciudades Rurales Sustentables, territorio, reconversión productiva, Estado, capitalismo, simulaciones, autonomía, utopías). UNAM-CIESAS: San Cristóbal de las Casas, Chiapas. Recuperado de: http://radiozapatista.org/? $p=5785$

González, N., y Ángeles, M. I. (2009). “Apuntes para repensar la teoría de la transición epidemiológica y su importancia para el diseño de políticas públicas". Espacios Públicos, I2(25), I5I-I62.

Good, C., y Corona de la Peña, L. E. (coords.) (20I I). Comida, cultura y modernidad en México. México: CONACYT-ENAH-INAH-Conaculta.

Guadarrama, G. (200I). Entre la caridad y el derecho. México: El Colegio Mexiquense-Consejo Estatal de Población (COESPO).

Gunder, A. (1982). La agricultura mexicana: transformación del modo de producción: 152 I-1630. México: Ediciones Era. Inegi (2010). Censo de Población y Vivienda. Principales resultados por localidad (ITER). Recuperado de: http://www. 
Bibliografía inegi.org.mx/sistemas/consulta_resultados/iter 2010 . aspx?c=27329\&s=est

INFACT Canadá (2006). "Scientific fraud and child health". Recuperado de: http://www.infactcanada.ca/ winter_2006_pg_I_2.htm

INSP (20I2). Encuesta Nacional de Salud y Nutrición (ENSANUT). México: Instituto Nacional de Salud Pública. Recuperado de: http://ensanut.insp.mx/informes/ENSANUT20 I2Resultados Nacionales2Ed.pdf

Juárez, J. L. (20I3). Nacionalismo culinario. La cocina mexicana en el siglo XX. México: Conaculta.

León, B. (20I4). Entre la redención y la conducción. El combate a la pobreza en México 1970-20I 2. México: Fontamara. Lorenzo, M. D. (20I I). El Estado como benefactor. Los pobres y la asistencia pública en la Ciudad de México I877-I 905. México: El Colegio Mexiquense-El Colegio de México. Mendoza, C. (0I de octubre de 20l4). Proposición del sen. Carlos Mendoza Davis, del grupo parlamentario del Partido Acción Nacional, con punto de acuerdo que exhorta a diversas autoridades a diseñar estrategias preventivas de abastecimiento y seguridad en las zonas vulnerables al impacto de fenómenos meteorológicos. México: Sistema de Información Legislativa. Recuperado de: http://sil. gobernacion.gob.mx/Archivos/Documentos/2014/10/ asun_3I50632_20I4I003_I4I2263327.pdf

Montesinos, R., y Martínez, V. G. (2000). “Empresarios, neoliberalismo y las miserias de la transición”. El Cotidiano, 16(100), 90-104. Recuperado de: http://www.redalyc. org/articulo.oa?id=325 I00 I I

OCDE (20I3). "México debe combatir la obesidad, asegura la OCDE”. México: Organización para la Cooperación y el Desarrollo Económico. Recuperado de: http:// www.oecd.org/mexico/Health-at-a-Glance-2013-PressRelease-Mexico_in-Spanish.pdf 
Ochoa Rivera, T. (20/3). "Alimentación y diferenciación Bibliografía social: el caso de una comunidad de México". Revista Internacional de Ciencias Sociales Interdisciplinares, 2(I), I-II.

Olmos, R. (20I5). El imperio financiero de los Legionarios de Cristo. México: Grijalvo.

Ortiz Gómez, A. S., Vázquez García, V., y Montes Estrada, M. (2005). "La alimentación en México: enfoques y visiones a futuro". Estudios Sociales, XIII(25), 8-34.

Oxfam Intermón (20I3). "Tras la marca. El papel de las diez grandes empresas de alimentación y bebidas en el sistema alimentario". Recuperado de: http://www. oxfamintermon.org/sites/default/files/documentos/files/ InformeTrasLaMarca.pdf

Oxfam México (20I3). "Los transgénicos amenazan la Cruzada Nacional contra el Hambre". Recuperado de: http:// www.oxfammexico.org/wp-content/uploads/2013/07/ bolet\%C3\%ADn-de-prensaCRUZADA-FINAL.pdf

Pilcher, J. (200I). ¡Vivan los tamales! La comida y la construcción de la identidad mexicana. México: CIESAS/Edicciones de la Reina Roja/Conaculta.

Ponce, J., Ávila, A., y Cabada, X. (16 de febrero de 2013). "Publicidad, expendio, programas públicos... un sistema alimentario perverso que nos enferma". La Jornada del Campo, p. 10.

Proceso (30 de noviembre de 2003). "Un Kilo de ayuda... para los Legionarios". Recuperado de: http://www. proceso.com.mx// 90633/un-kilo-de-ayuda-para-loslegionarios

Rodríguez Castillo, L. (20I4). "Acción pública y desarrollo social en el sureste de México: la agenda Chiapas-ONU". Liminar. Estudios Sociales y Humanísticos, XII(2), I63-I80.

Rodríguez Wallenius, C. A. (20I4). "Ciudades rurales en Chiapas. Mecanismos institucionales para el despojo", 
Bibliografía en F. Novel Urdanivia (coord.), Instituciones y Desarrollo (pp. 305-324). México: UAM Xochimilco.

Rubio, B. (20I3). "La crisis alimentaria en México”, en B. Rubio (coord.), La crisis alimentaria mundial y su impacto sobre el campo mexicano (pp. 53-82). México: Instituto de Investigaciones Sociales (IIS), UNAM-Miguel Ángel Porrúa.

(20।4). El dominio del hambre. Crisis de hegemonía y alimentos. México: Universidad Autónoma ChapingoDirección de Centros Regionales UniversitariosColegio de Posgraduados-Universidad Autónoma de Zacatecas-Unidad Académica y Estudios del DesarrolloJuan Pablos Editor.

Sagarpa (20I3). Anuncia el presidente Enrique Peña Nieto acciones conjuntas entre sectores público, privado y social contra el hambre. Recuperado de: http://www.sagarpa.gob.mx/ saladeprensa/discursos20 I 2-20 I8/Paginas/20I3D005. aspx

Salas-Porras, A. (20|4). "Las élites neoliberales en México: ¿cómo se construye un campo de poder que transforma las prácticas sociales de las élites políticas?”. Revista Mexicana de Ciencias Políticas y Sociales, LIX(222), 279$3 \mid 2$.

Sedesol (s/f). Objetivos de la Cruzada Nacional contra el Hambre (gráfico interactivo). Recuperado de: http:// www.sedesol.gob.mx/work/models/SEDESOL/Cruzada/ objetivos_indicadores $2 /$ index.html

- (20I3). Lineamientos específicos para la operación del Programa Comedores Comunitarios en el estado de Guerrero, en el marco de la Cruzada contra el Hambre para el ejercicio fiscal 2013. Recuperado de: http://www. normateca.sedesol.gob.mx/work/models/NORMATECA/Normateca/I_Menu_Principal/2_Normas/3_Historico/20I4/Lineamientos_Programa_Comedores_ Comunitarios_Guerrero_240I20I4.pdf 
(20I4). "Firma la Sedesol convenios de colaboración con OSC e instituciones públicas de nutrición y salud". Recuperado de: http://www.gob.mx/sedesol/prensa/ firma-la-sedesol-convenios-de-colaboracion-con-osce-instituciones-publicas-de-nutricion-y-salud

Secretaría de Economía (2013). Industria de alimentos procesados. Recuperado de: http://mim.promexico.gob.mx/ work/sites/mim/resources/LocalContent/72/2/Alimentos_procesados_ES.pdf

SINHAMBRE (20I3). "Lineamientos de Organización y Funcionamiento del Consejo de Expertos contra el Hambre". Recuperado de: http://sinhambre.gob.mx/wp-content/ uploads/2014/02/9_COMITE_DE_EXPERTOS.pdf

- (20I5). "Evaluación de la Cruzada Nacional contra el Hambre". Recuperado de: http://sinhambre.gob.mx/ wp-content/uploads/2015/02/04_CONEVAL.pdf

Torres, T. F. (20I4). Canasta básica y calidad de la alimentación en México. México: Ariel-UNAM-CIAD.

Torres Oregón, F. (I6 de mayo de 20I4a). Entrevista personal con comisario municipal de Atliaca, municipio de Tixtla de Guerrero, Guerrero.

(I4 de mayo de 20।4b). Entrevista personal a director de la Secundaria Técnica No. 133 "Plan de Ayutla". Metlatónoc, Guerrero.

(06 de marzo de 20I5). Entrevista personal con director del Banco de Alimentos en la ciudad de Toluca, México.

Torres Salcido, S. G. (20I0). Distribución de alimentos. Mercados y políticas sociales. México: CEIICH-UNAM.

(20I I). El futuro de la alimentación en México: ¿nuevos riesgos? (material audiovisual). México: Instituto de Investigaciones Sociales (IIS) UNAM. Recuperado de: http://mediacampus.cuaed.unam.mx/node// 735

Turati, M. (2013). "Estrategia mediática”. Proceso, (19II), 6-II. 

\begin{tabular}{c|c} 
Bibliografía & $\begin{array}{c}\text { Veraza, J. (coord.) (2008). Los peligros de comer en el capi- } \\
\text { talismo. México: Itaca. }\end{array}$
\end{tabular}

\section{Anexo I. Informes financieros de empresas de agroindustria en México}

Estados de
resultados
financieros
FEMSA (Coca
Cola)

Año 2007. Recuperado de: http://files.shareholder.com/ downloads/FEMSAS/161926957x0x190258/58BB3A887B34-4712-A7C4-871E18C5BF69/2007AR_es.pdf;

Año 2008. Recuperado de: http://files.shareholder.com/ downloads/FEMSAS/161926957x0x282663/C823BFD88C8F-4006-B334-C965C9AA1128/Annual_Report_08_ full_SPANISH.pdf

Año 2009. Recuperado de: http://files.shareholder.com/ downloads/FEMSAS/161926957x0x368914/39C02BCEE52A-481D-AC41-1501CA1694AF/FEMSA_Informe_ Anual_2009_Espa_ol.pdf

Año 2010. Recuperado de: http://files.shareholder.com/ downloads/FEMSAS/161926957x0x454459/BF9338A9D46E-4F60-93FE-D227F841E75D/FEMSA_Annual_ Report_SP.pdf

Año 2011. Recuperado de:http://files.shareholder.com/ downloads/FEMSAS/161926957x0x555081/1A380BF90F9E-43C9-88FB-7C7EB4B0F897/femsa_AR11spa.pdf Año 2012. Recuperado de: http://files.shareholder.com/ downloads/FEMSAS/161926957x0x646163/E79DF9CF7D9C-4DEF-9ECD-91FF3EEA538F/FEMSA_AR12_SPA. pdf

2013:http://files.shareholder.com/downloads/ FEMSAS/161926957x0x733737/ED1E8F83-97AD-477689C1-2AE2B2D4078E/femsaAR_spa13.pdf Año 2014. Recuperado de :http://files.shareholder.com/ downloads/FEMSAS/161926957x0x816924/EAE3A7CDEECC-4656-879C-AF94F887AD8D/FEMSA_Informe_ Anual_2014_Spa_.pdf

\section{6}


Papel de la industria alimentaria y de la sociedad civil en los comedores comunitarios de SINHAMBRE. Casos de la Montaña y centro de Guerrero

\begin{tabular}{ll}
\hline Estados de & Año 2007-2008. Recuperado de: http://www. \\
resultados & cultiba.mx/inversionistas/Informe\%20Anual/2008/ \\
financieros & EstadosFinancieros.pdf \\
Pepsico & Año 2010. Recuperado de: http://www.bmv.com.mx/ \\
& infoanua/infoanua_386592_1.pdf \\
& Año 2011-2012. Recuperado de: http://www.cultiba.mx/ \\
& inversionistas/Informe\%20Anual/2012/InformeAnual. \\
& pdf \\
& Año 2013. Recuperado de: http://www.bmv.com.mx/ \\
& eventore/eventore_505446_2.pdf \\
\hline Estados & Año 2009. Recuperado de: http://www.nestle.com.mx/ \\
financieros & media/pressreleases/fuerte-desempeo-en-ventas-y- \\
Nestlé & rentabilidad-de-nestl-en-2009 \\
& Año 2010. Recuperado de: http://www.nestle.com.mx/ \\
& media/pressreleases/crecimiento-orgnico-en-el-primer- \\
& semestre-y-mejora-en-el-margen-de-ebit-se-reconfirma- \\
& el-panorama-de-todo-el-ao \\
& Año 2011. Recuperado de: http://www.nestle.com.mx/ \\
& media/pressreleases/news2011primersemestre \\
& Año 2012. Recuperado de: http://www.nestle.com.mx/ \\
& media/pressreleases/resultados-financieros-de-9-meses \\
& Año 2013. Recuperado de: http://www.nestle.com.mx/ \\
& media/pressreleases/resultados-financieros-2013 \\
\hline Bimancieros & Año 2008-2009. Recuperado de: http://www. \\
& mzweb.com.br/grupobimbo/web/arquivos/Bimbo_ \\
& ReporteAnual_2010_port.pdf \\
& Año 2010-2013. Recuperado de: http://www.grupobimbo. \\
& com/informe/Bimbo-Informe-Anual-2013/dm/f46.pdf \\
\hline & \\
&
\end{tabular}

\section{Anexo 2. Sitios web con información de empresas de agroindustria mencionadas}

Femsa (Coca Cola): http://www.femsa.com/

Pepsico: http://www.pepsico.com.mx/Brands.html

Nestlé: http://www.nestle.com.mx/brands/refrigerados

Grupo Bimbo: http://grupobimbo.com/es/index.html 